\title{
Larvicidal and Synergistic Activities of Crude Leaf Extracts of Pyrethrum (Chrysanthemum), Eucalyptus camaldulensis Sm. (Myrtaceae) and Nicotiana tabaccum (Tobacco) against the Larvae of the Malaria Vector Anopheles gambiae s.s. Giles (Diptera: Culicidae)
}

\author{
Glenn O. Araka ${ }^{1}$, Prof. John Ochora ${ }^{2}$, Prof. Johnstone Wakhisi ${ }^{3}$, Dr. Festus Tolo ${ }^{4}$, \\ Prof. B.O. Khwa-Otsyula ${ }^{5}$ \\ ${ }^{1}$ (Msc, Lead Researcher), Lecturer, Department of Environmental Health, School of Public Health, \\ Moi University, Eldoret, Kenya \\ ${ }^{2}(\mathrm{PhD})$, Department of Botany, School of Biological Sciences, Jomo Kenyatta University of \\ Agriculture and Technology (JKUAT), Nairobi, Kenya \\ ${ }^{3}(\mathrm{PhD})$, Department of Medical Biochemistry, Moi University, Eldoret, Kenya \\ ${ }^{4}(\mathrm{PhD})$, Senior Researcher, Kenya Medical Research Institute (KEMRI), Nairobi, Kenya \\ ${ }^{5}$ (Professor of Surgery, Department of Surgery and Anesthesiology, School of Medicine, \\ Moi University, Eldoret, Kenya
}

\begin{abstract}
The present study was undertaken to evaluate larvicidal efficacy of crude leaf extracts of Pyrethrum, Eucalyptus camaldulensis and Nicotiana tabaccum individually and in combination (synergistic activities) of the extracts against third instar larvae of Anopheles gambiae s.s. Giles. In the individual extract tests it was found that pyrethrum DCM extract exhibited best activity achieving $100 \%$ mortality of third instar larvae at $L C_{50} 164.86 \mathrm{ppm}$ and $L C_{90} 255.17 \mathrm{ppm}$. This was followed by the DCM extract of Eucalyptus camaldulensis $\left(L C_{50} 168.58 \mathrm{ppm}, L C_{90} 315.85 \mathrm{ppm}\right)$. Nicotiana tabaccum was third $L C_{50}\left(189.58 \mathrm{ppm}, \mathrm{LC} \mathrm{C}_{90} 320.75 \mathrm{ppm}\right)$. The results revealed that pyrethrum extract was more toxic plant when tested individually. In the synergistic tests a total of 30 combinations of extracts (comprising of 30 treatments) amongst the three plants were tested. It was observed that the maximum synergistic activities were found in the combination extracts of DCM and Methanol in the ratio 1:1 (v/v) (pyrethrum and Eucalyptus camaldulensis extracts respectively) at 118.65 ppm. Other combinations that exhibited good activities were DCM combination of ethyl acetate (pyrethrum and Eucalyptus camaldulensis extracts respectively), DCM combination of hexane (Pyrethrum and Nicotiana tabaccum extracts respectively) and DCM combination of hexane (Eucalyptus camaldulensis and Nicotiana tabaccum extracts respectively).These combinations exhibited appreciable activities by achieving 100\% larval mortality at 121.45, 127.85, 130.78 and 135.55 ppm respectively. The results of the study revealed that pyrethrum plant leaves individual and/or combinations with extracts of Eucalyptus camaldulensis and Nicotiana tabaccum can be used as a potent source of natural mosquito larvicidal agent to replace the synthetic insecticides.
\end{abstract}

Keywords: Pyrethrum, E. camaldulensis, Nicotiana tabaccum, synergistic, crude leaf extracts, combination extracts, third instar larvae, larval mortality

\section{Introduction}

Mosquitoes are blood sucking insects and through this habit they transmit disease agents that cause malaria, dengue, yellow fever, encephalitis, West Nile fever and filariasis. Human malaria is commonly reported in tropical and sub-tropical regions of the world and is caused by infection with Plasmodium falciparum, P.vivax, P.ovale or P. malariae (1), which are transmitted to humans only by Anopheles mosquitoes. In Africa malaria is endemic in Sub-Saharan Africa. Mosquitoes transmit malaria to more than 700 million people each year and remain the major source of illness and death world-wide (2) contributing to poverty and mortality thus affecting socio-economic development in tropical and sub-tropical countries (3). Dengue fever is the most common life threatening viral infection with no proper vaccine or treatment (4). It is transmitted by bite of infected Aedes aegypti (4) and affects 50 million people a year and 2.5 billion at risk (5).
Mosquito control is high in demand for managing the spread of disease agents mosquitoes transmit. Currently, control strategies are based on mainly the use of conventional synthetic chemical insecticides. The effectiveness of these chemicals for vector control is rendered unproductive when mosquitoes develop resistance to insecticides as a result of their repeated use. Coupled with this, the use of sysnthetic chemical insecticides presents the potential for environmental pollution and some evidence suggests these substances act as immunosuppressants (7).

To counteract the negative effects of synthetic chemical insecticides to the environment interest in alternatives has developed and continuous evaluation and use of plant extracts with insecticidal activity are being preferred for mosquito control. This is because the botanical insecticides have advantages which include safety to humans and animals, rapid breakdown of the toxic molecules in the environment and comparatively few 


\section{International Journal of Science and Research (IJSR) \\ ISSN (Online): 2319-7064}

Index Copernicus Value (2013): 6.14 | Impact Factor (2015): 6.391

adverse effects to non-target organisms. For example Pushpanathan et al., (2006) (8) and Thangam and Katheresan (1991) (9) have studied a number of extracts from terrestrial plants for toxicity to larvae of Anopheles mosquitoes, including those from Calophyllum inophyllum (Chusiaceae), Rhinacanthus nasutus (Acanthaceae), Solanum suratense, (Solanaceae), Samadera indica (Simaroubaceae) and Myriophyllum spicatum (Haloragaceae). This also includes the study of Sargassum Withii Greville (Sargassaceae) which is an abundant marine brown alga commonly found in the shorelines of India. It is a macroscopic, multicellular, photosynthetic, non vascular, pelagic marine species (10) rich in sulphated polysacchrides that manifest potent free radical scarvenging (11) and antioxidant (12) effects.

Synergistic activity between pesticides is a powerful and effective tool for the development of an efficient, more eco-friendly and less hazardous insect pest control strategy (Benard and Philogene, 1993) (13). The application of synergists has been preferred as a strategy to enhance the eco-friendliness and cost-effectiveness of an insecticide by reducing the quantity needed to kill the target population and lengthen the residual activity. The role of synergists in resistance management is an accepted alternative for resistance management. The importance of proper selection of plant extracts as synergists in mixed formulations with different other plant extracts or synergistic insecticides is being increasingly recognized in mosquito management. The mixture may provide less toxicity, prevent the development of resistance, have economic benefits and could be more effective than individual components of the mixture. Synthetic phytopesticide combinations are rarely evaluated as mosquito larvicides (14). In the present investigation, the joint action of Pyrethrum and Eucalyptus camaldulensis, pyrethrum and Nicotiana tabaccum and Eucalyptus and Nicotiana tabaccum crude leaf extracts in their various solvent extracts were evaluated against the third instar larvae of the malaria vector, Anopheles gambiae s.s Giles.

\section{Materials and Methods}

\subsection{Plants collection and preparation}

Leaves of pyrethrum were collected (already dried) from Pyrethrum Board of Kenya (PBK), Stanely Mathenge Road, Nakuru, Kenya. The leaves of Eucalyptus camaldulensis from mature trees were collected from the lead researcher's farm, Molo sub-district, Kenya and leaves of Nicotiana tabaccum were collected from $\mathrm{Mr}$ Meshack Wasike farm in Malakhisi location, Bungoma district, Kenya. The leaves of E. camaldulensis and Nicotiana tabaccum were cleaned and dried in shade for 25-30 days. The leaves of the three plants were then chopped ground into fine powder. One hundred grams of each plant were extracted mechanically using a commercial stainless steel blender then $1 \mathrm{~kg}$ of powdered leaves were macerated using non-polar and polar solvents
(Dichloromethane (DCM), methanol, ethyl, acetate, ethanol, hexane, and aqueous). In each solvent the plant material was soaked for 48 hours at $35^{\circ} \mathrm{C}$ and filtered twice using a fine cloth and then Watman No. 1 filter paper (12 x $15 \mathrm{~cm})$ to obtain the extract and to the same residue the same solvent was added again. The procedure was repeated twice to obtain maximum extract. The extracts were concentrated at reduced temperature using a rotary vacuum evaporator and stored in air-tight amber or blue bottles at $4^{0} \mathrm{C}$ until when required for use. From the stock solutions of the extracts, varying concentrations of each extract were prepared (50, 100, 150, 200, 250, 300350 and $400 \mathrm{ppm})$, and these concentrations were used for larvicidal bioassays. All chemicals used in this study were of extreme pure grade obtained from Kenya Medical Research Institute (KEMRI), Kisumu, Kenya.

\subsection{Mosquito collection and rearing}

By using a mouth aspirator, adult male and female Anopheles gambiae s.s. Giles mosquitoes were collected from Langas area of Eldoret County in the ratio of 3:1 (Male: Female) and were cultured in cages (30 x 30 x $30 \mathrm{~cm}$ ). The mosquitoes were fed with $10 \%$ sucrose solution soaked in cotton wool. Female mosquitoes were fed with rat blood providing them protein for hatching by the rat back hairs cut and shaved leaving bear skin and then put in the mosquito cages.

\subsection{Anopheles gambiae s.s. Giles Culture}

Male and female An. gambiae s.s. Giles mosquitoes in the same cage were allowed to mate. Female mosquitoes laid eggs on a plastic bowl 12 inches in diameter, on which a filter paper stripe was placed (lined) inside. The bowl was filled with water to nearly full. The filter paper served as a substrate for mosquito eggs. The filter paper stripe full of eggs was removed and dried at room temperature and then kept at $20^{\circ} \mathrm{C}$ in the period of the study. Eggs were collected and allowed to hatch in a filled water container (plastic bowl). This approach was meant to maintain larvae of the same age within a period of 2-4 days. There are four stages of An. gambiae s.s. Giles larvae development i.e. first instar, second instar, third instar and fourth instar. The larvae were fed with brewers yeast and dog biscuits (3:1) on water surface. Some of the third instar larvae were used to test with the extracts.

\subsection{Experimental design}

In this study experiments were set up as complete randomized design (CRD). They were in two main parts in which each part three experiments were performed totaling to six units of experiments as shown in figures 1(a) and 1(b) below:

Part 1: Effects of individual extracts on third instar larvae of Anopheles gambiae s.s. Giles. 
International Journal of Science and Research (IJSR)

ISSN (Online): 2319-7064

Index Copernicus Value (2013): 6.14 | Impact Factor (2015): 6.391

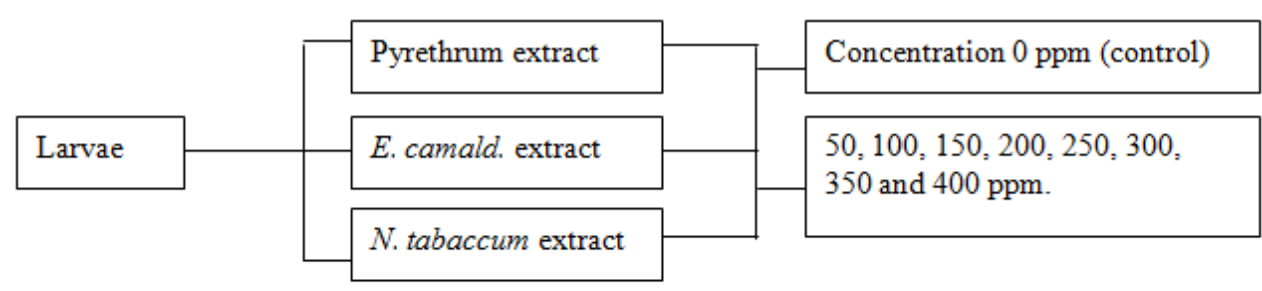

Fig 1(a) Experimental design of individual extracts

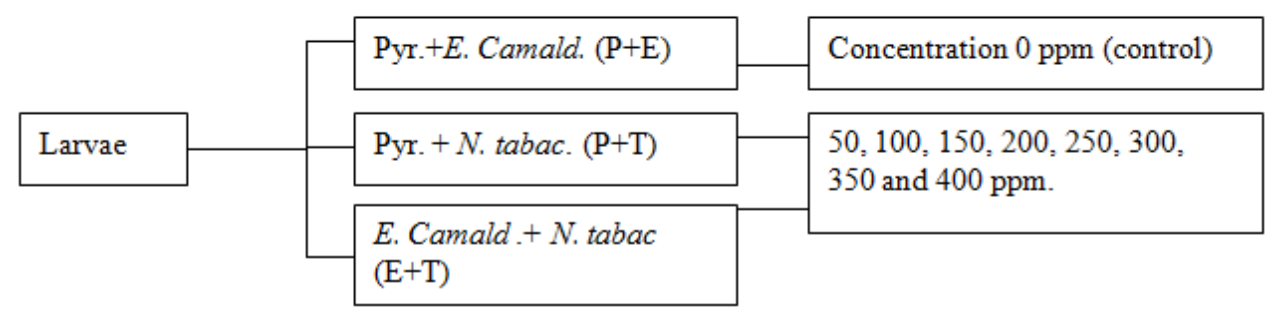

Figure 1(b): Experimental design of combination extracts

The third instar larvae of Anopheles gambiae s.s. Giles were exposed to broad ranges of test concentrations of each crude leaf extract to determine the activity range of each extract $\{$ Part 1 Fig 1(a)\} and the larvae were also exposed to combination crude leaf extract oils \{Part 1 Fig 1(b)\}. Susceptibility tests were carried out using WHO insecticide susceptibility procedures (1981) (15). All experiments were performed under conducive laboratory conditions $\left(27 \pm 2^{0} \mathrm{C} ; 75 \pm 5 \mathrm{RH}\right.$ and $14: 10$ dark photo period.

\subsection{Materials}

\subsubsection{Anopheles gambiae s.s. Giles rearing}
a) Rats
b) Earth - wave or plastic bowl (diameter 12 inches)
c) Mosquito rearing cages $(30 \times 30 \times 30 \mathrm{~cm})$ with nets
d) Brewers yeast and dog biscuits (3:1)
e) Sucrose solution (10\%)
f) Cotton cloth

\subsubsection{Equipment}

a) Membrane filter $47 \mathrm{~mm}$ in diameter or $(12 \times 25 \mathrm{~cm})$ Whatman No. 1

b) Dry oven

c) Blender

d) Rotary evaporator

Buchi

e) Vacuum pump

f) Beakers $(50,100,250,500$ and $1000 \mathrm{ml})$

g) Conical flask $(100,250$, and $500 \mathrm{ml})$

h) Pipettes $(1,5$ and $10 \mathrm{ml})$

i) Measuring cylinders $(10,50,100,250$ and $500 \mathrm{ml}$

j) Petri dishes

k) Test tubes ( 6 in $x \frac{3 / 4}{4}$ in)

l) Dropper

m) Glass funnel

n) Sprayer bottle

\section{Methodology}

3.1 Effects of the individual extract on the third instar larvae of Anopheles gambiae s.s. Giles.

Under this procedure three experiments in the order of pyrethrum crude leaf extract effect on the larvae, Eucalyptus camaldulensis crude leaf extract effect on the larvae and Nicotiana tabaccum crude leaf extract effect on the larvae were carried out (Table 1) as described below:

Experiment 1: The effect of pyrethrum crude leaf extract on the third instar larvae of Anopheles gambiae s.s. Giles.

The effects of pyrethrum crude leaf extract on the mortality of An. Gambiae s.s. Giles were investigated. Twenty (20) $\mathrm{ml}$ of each concentration for each plant extract was put into $50 \mathrm{ml}$ beakers and then 25 third instar larvae were dipped into the beakers. Mortality of the larvae was observed at the end of 24 hours exposure by counting the number of dead third instar larvae. Larvae were confirmed dead when they failed to move after probing them with a needle at their cervical region. Moribund larvae were those incapable of rising to the surface when the test solutions were disturbed gently. Calculation of the percentage of mortality of third instar larvae from three replications of each treatment determined lethal concentration $\left(\mathrm{LC}_{50}\right)$.

Experiment 2: The effects of Eucalyptus camaldulensis crude leaf extract on the mortality of third instar larvae of An. Gambiae s.s. Giles.

Twenty (20) ml of each concentration was put into $50 \mathrm{ml}$ beakers followed by dipping into solution 25 third instar larvae. The effect of the concentrations upon the third instar larvae was observed at 24 hours exposure. The numbers of dead third instar larvae were counted. Larvae were confirmed dead when they failed to move after probing them with a needle at their cervical region. Moribund larvae were those incapable of rising to the surface when the test solutions were disturbed gently. 


\section{International Journal of Science and Research (IJSR) \\ ISSN (Online): 2319-7064 \\ Index Copernicus Value (2013): 6.14 | Impact Factor (2015): 6.391}

Percentage of mortality was calculated based on three replicates of each treatment in order to determine lethal concentration $\left(\mathrm{LC}_{50}\right)$.

Experiment 3: The effects of Nicotiana tabaccum crude leaf extract on the mortality of third instar larvae of Anopheles gambiae s.s. Giles.

Twenty (20) $\mathrm{ml}$ of each concentration was put into $50 \mathrm{ml}$ beakers followed by dipping into solution 25 third instar larvae. Mortality was observed at 24 hours exposure by counting the number of dead third instar larvae. Larvae were confirmed dead when they failed to move after probing them with a needle at their cervical region. Moribund larvae were those incapable of rising to the surface when the test solutions were disturbed gently. Percentage of mortality of third instar larvae was calculated based on three replicates of each treatment, hence determined lethal concentration $\left(\mathrm{LC}_{50}\right)$.

3.2 The efficacy of crude leaf extract combination on the mortality of the third instar larvae of Anopheles gambiae s.s. Giles.

Three experiments were performed in this procedure and a total of thirty (30) treatments were carried out in an equal basis P + E (10), P+ T (10) and E+T (10) see Table 2.

\subsubsection{Effects of combination extracts}

Experiment 1: The effects of pyrethrum crude leaf extract in combination with Eucalyptus camaldulensis crude leaf extract (i.e $P+E$ ) on third instar larvae of Anopheles gambiae s.s. Giles.

The synergistic effect of crude leaf extract combination $(\mathrm{P}+\mathrm{E})$ on the mortality of third instar larvae of Anopheles gambiae s.s. Giles were investigated. In this experiment ten (10) treatments were performed using combination of various solvents ( see Table 2 ).

Twenty $\mathrm{ml}$ of pyrethrum crude leaf extract and $20 \mathrm{ml}$ of Eucalyptus camaldulensis (Ratio 1:1 v/v) of various solvent extract were put into $100 \mathrm{ml}$ beakers and 25 third instar larvae were dipped into the test solutions in beakers. Mortality of third instar larvae was observed at 24 hours exposure by counting the number of dead third instar larvae. Larvae were confirmed dead when they failed to move after probing them with a needle at their cervical region. Moribund larvae were those incapable of rising to the surface when the test solutions were disturbed gently. Percentage of mortality was calculated from three replicates of each treatment and thus determined lethal concentration $\left(\mathrm{LC}_{50}\right)$. The synergistic factor (SF) was calculated for each extract combination using Kalyanasandaram and Babu formula (1982) (16) and Kalyanasandaram and Das (1985) (17).

$\mathrm{SF}=\underline{\mathrm{LC}}_{50}$ value of the individual plant extract

$\mathrm{LC}_{50}$ value of the combined plant extracts
A value more than one, confirms synergism, the greater the value, the higher the synergistic activity. An SF value less than one indicate antagonism.

Experiment 2: The effects of pyrethrum crude leaf extract combined with Nicotiana tabaccum crude leaf extract (i.e. P+T) on An. gambiae s.s. Giles third instar larvae.

The synergistic effect of the combined (pyrethrum and Nicotiana tabaccum) crude leaf extracts on the mortality of third instar larvae of An. gambiae s.s. Giles were investigated. As in $\mathrm{P}+\mathrm{E}$ in experiment 1 above $20 \mathrm{mls}$ of pyrethrum and $20 \mathrm{mls}$ of Nicotiana tabaccum ( ratio 1:1, v/v ) were put into $100 \mathrm{ml}$ beakers and 25 third instar larvae were dipped into the solutions in beakers. Mortality of third instar larvae was recorded at 24 hour exposure by counting the number of dead third instar larvae. Larvae were confirmed dead when they failed to move after probing them with a needle at their cervical region. Moribund larvae were those incapable of rising to the surface when the test solutions were disturbed gently. Percentage of mortality was calculated from three replicates of each treatment and therefore determined lethal concentration $\left(\mathrm{LC}_{50}\right)$.

Experiment 3: The synergistic effects of Eucalyptus camaldulensis and Nicotiana tabaccum (i.e. E+T) crude leaf extracts on Anopheles gambiae s.s. Giles.

The synergistic effects of crude leaf extracts combination $(\mathrm{E}+\mathrm{T})$ on the mortality of third instar larvae of $A n$. gambiae s.s. Giles was investigated. As in the first and second experiments $20 \mathrm{mls}$ of Eucalyptus camaldulensis crude leaf extract and 20 mls of Nicotiana tabaccum crude leaf extracts ( ratio $1: 1 \mathrm{v} / \mathrm{v}$ ) were put in $100 \mathrm{ml}$ beakers and into them were dipped 25 third instar larvae. Mortality of the third instar was observed at 24 hours exposure by counting the number of dead larvae. Larvae were confirmed dead when they failed to move after probing them with a needle at their cervical region. Moribund larvae were those incapable of rising to the surface when the test solutions were disturbed gently. Percentage of morbidity was calculated from three replicates of each treatment and thus determined lethal concentration (LC50).

\subsection{Statistical Analysis}

Mortality of insects was determined at the end of 24 hours exposure. The average larval mortality data were subjected to profit analysis for calculating $\mathrm{LC}_{50}$ and $\mathrm{LC}_{90}$ and other statistics at 95\% fiducial limits of upper confidence limit (UCL) and lower confidence limit (LCL) and Chi- square values were calculated using the SPSS 20.0 (Statistical Package of Social Sciences) software. Percent mortality was corrected by using Abbott's formula (Abbott 1925) (18). Lethal concentration $\left(\mathrm{LC}_{50}\right)$ with their 95\% confidence limits of the activities were determined using Log probit analysis test (Finney, 1971) (19). 


\section{International Journal of Science and Research (IJSR) \\ ISSN (Online): 2319-7064 \\ Index Copernicus Value (2013): 6.14 | Impact Factor (2015): 6.391}

\section{Results}

Table 1 shows the activities of individual crude leaf extract of pyrethrum, Eucalyptus camaldulensis and Nicotine tabaccum applied as a 24 hour bioassay study at 50, 100,
200, 250, 300, 350 and 400 ppm against third instar larvae of Anopheles gambiae s.s. Giles. The result showed highest toxicity value of $164.86 \mathrm{ppm}$ for DCM crude leaf

Table 1: The effects of individual crude leaf extracts on the third instar larvae of Anopheles gambiae s.s. Giles.

\begin{tabular}{|c|c|c|c|c|c|c|}
\hline \multirow[t]{2}{*}{ Name of plant } & \multirow[t]{2}{*}{ Extract solvent } & \multirow[t]{2}{*}{$L C_{50}($ ppm $)$} & \multicolumn{2}{|c|}{ Fiducial limits } & \multirow[t]{2}{*}{ Regression equation } & \multirow[t]{2}{*}{$\begin{array}{c}\text { Chi-square value } \\
(x 2)\end{array}$} \\
\hline & & & Upper & Lower & & \\
\hline \multirow{6}{*}{ Pyrethrum } & Ethanol & 187.78 & 179.78 & 196.53 & $0.7470+1.7758 x$ & 4.5217 \\
\hline & Methanol & 222.45 & 209.85 & 238.71 & $0.4684+1.9089 x$ & 10.6452 \\
\hline & DCM & 164.86 & 161.57 & 176.28 & $0.7336+1.7893 x$ & 14.2584 \\
\hline & Hexane & 230.66 & 214.79 & 252.67 & $0.5566+1.9098 x$ & 19.5759 \\
\hline & Ethylacetate & 227.56 & 219.77 & 269.96 & $0.4899+1.9078 x$ & 19.5759 \\
\hline & Aqueous & 247.84 & 233.37 & 267.72 & $0.6758+1.2123 x$ & 18.6202 \\
\hline \multirow{6}{*}{$\begin{array}{c}\text { Eucalyptus } \\
\text { Camaldulensis }\end{array}$} & Ethanol & 210.15 & 193.88 & 232.07 & $0.7686+1.9694 x$ & 4.6621 \\
\hline & Methanol & 197.46 & 189.61 & 208.69 & $0.4868+1.9227 x$ & 13.256 \\
\hline & DCM & 168.65 & 152.44 & 176.95 & $0.6975+1.9567 x$ & 10.4532 \\
\hline & Hexane & 198.56 & 181.66 & 220.45 & $0.7086+1.8685 x$ & 9.5033 \\
\hline & Ethylacetate & 260.56 & 240.77 & 289.96 & $0.05886+1.7825 x$ & 14.0773 \\
\hline & Aqueous & 259.58 & 239.87 & 288.87 & $0.05977+1.8365 x$ & 6.7556 \\
\hline \multirow{6}{*}{ Nicotiana tabaccum } & Ethanol & 189.58 & 181.50 & 298.42 & $0.7376+1.8898 x$ & 3.5463 \\
\hline & Methanol & 224.35 & 211.73 & 240.86 & $0.4988+1.8985 x$ & 3.8642 \\
\hline & DCM & 229.72 & 216.80 & 246.63 & $0.5878+1.9874 x$ & 15.5740 \\
\hline & Hexane & 235.85 & 221.25 & 240.53 & $0.5663+1.9096 x$ & 4.6542 \\
\hline & Ethylacetate & 201.52 & 191.00 & 213.84 & $0.6455+1.8990 \mathrm{x}$ & 14.0773 \\
\hline & Aqueous & 258.42 & 238.79 & 287.58 & $0.0608+2.1015 x$ & 6.4444 \\
\hline
\end{tabular}

Extract of pyrethrum seconded by DCM crude leaf extract of Eucalyptus camaldulensis at 168.65 ppm. Both of these extracts achieved $100 \%$ larval mortality. Ethanol crude leaf extract of pyrethrum showed high activity as well at 181.78 ppm causing a mortality of $92.5 \%$. Two crude leaf extracts of Eucalyptus camaldulensis showed the lowest activities that of aqueous solvent and ethyl acetate solvent at $259.58 \mathrm{ppm}$ and $260.56 \mathrm{ppm}$ respectively and causing larval mortality of $80.8 \%$ and $78.6 \%$ respectively. It was observed that the plant crude leaf extracts indicated dose dependent mortality of the tested larvae. The $\mathrm{LC}_{50}$ value with other associated values such s 95\% fuducial limit, regression equation and Chi - square were given in table 1. Table 2 shows individual and combination extracts in order to calculate synergistic factor (SF). In this test it was observed that when the crude leaf extracts were combined in the ratio of $1: 1(\mathrm{v} / \mathrm{v}) 15$ pairs indicated synergistic activity, 10 pairs acted antagonistic and 2 pairs were neither synergistic nor antagonistic.

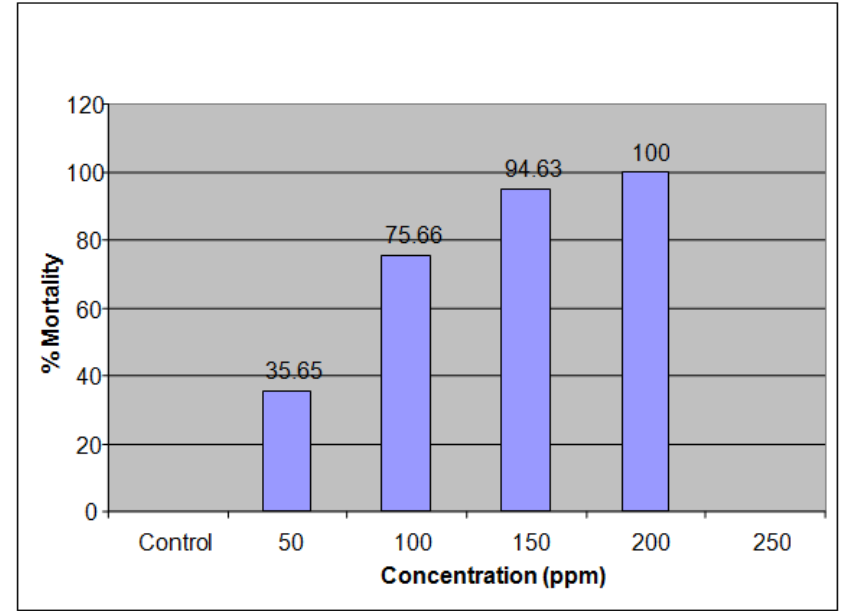

Figure 1: Percent Larval mortality of third instar larvae of An. gambiae s.s. Giles against DCM leaf extracts of Pyrethrum



Figure 2: Percent Larval mortality of third instar larvae of An. gambiae s.s. Giles against DCM leaf extract of Nicotiana tabaccum 


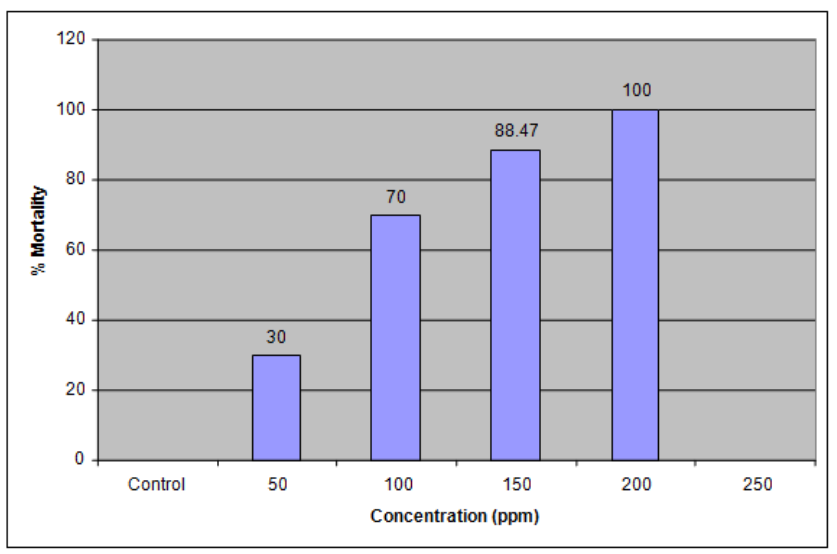

Figure 3: Percent Larval mortality of third instar larvae of An. gambiae s.s. Giles against DCM leaf extracts of $E$. camaldulensis

Table 2: The effect of crude leaf extract combination of the plants pyrethrum, Eucalyptus camaldulensis and Nicotiana tabaccum

\begin{tabular}{|c|c|c|c|c|c|c|c|c|}
\hline Plant & Ratio & Combination solvent extracts & Individu & $C_{50} \mathrm{Ppm}$ & $\begin{array}{c}\text { Combination } \\
L C_{50} \mathrm{ppm}\end{array}$ & & & effect \\
\hline & & Ethanol +Aqueous Methanol & 187.78 & 210.15 & 152.85 & 1.2285 & 1.3749 & $\mathrm{~S}$ \\
\hline Pyr. + Eucalyptus & $1: 1$ & +Ethyl acetate & 224.45 & 260.56 & 189.54 & 1.736 & 1.3747 & $\mathrm{~S}$ \\
\hline & & DCM + Hexane & 164.86 & 168.65 & 127.85 & 1.2894 & 1.3191 & $\mathrm{~S}$ \\
\hline & & Ethanol +Aqueous Methanol & 187.78 & 189.58 & 146.64 & 1.2855 & 1.2928 & $\mathrm{~S}$ \\
\hline $\mathrm{Pyr}+N$. tabaccum & $1: 1$ & +Ethyl acetate & 224.45 & 224.35 & 232.66 & 0.9561 & 0.9643 & A \\
\hline & & DCM + Hexane & 164.86 & 229.72 & 130.78 & 1.2606 & 1.7565 & $\mathrm{~S}$ \\
\hline & & Ethanol +Aqueous Methanol & 210.15 & 258.42 & 242.80 & 0.8655 & 1.0643 & SA \\
\hline E. camala.. $+N$. & $1: 1$ & +Ethyl acetate & 197.46 & 201.52 & 219.45 & 0.8998 & 0.9182 & A \\
\hline & & DCM + Hexane & 168.65 & 235.85 & 135.55 & 1.2442 & 1.7399 & $\mathrm{~S}$ \\
\hline & & Methanol + Aqueous & 224.45 & 259.58 & 201.55 & 1.1136 & 1.2879 & $\mathrm{~S}$ \\
\hline & & DCM + Aqueous & 164.86 & 259.58 & 151.75 & 1.0864 & 1.7106 & $\mathrm{~S}$ \\
\hline & & DCM +Methanol & 164.86 & 197.46 & 118.65 & 1.3895 & 1.6642 & $\mathrm{~S}$ \\
\hline Pyr. + E. camald. & $1: 1$ & DCM +Ethyl acetate & 164.86 & 260.56 & 121.45 & 1.3574 & 2.1454 & $\mathrm{~S}$ \\
\hline & & Methanol +Ethyl acetate & 224.45 & 260.56 & 230.50 & 0.9651 & 1.1304 & SA \\
\hline & & Methanol + Hexane & 197.46 & 198.56 & 147.46 & 1.3391 & 1.3465 & $\mathrm{~S}$ \\
\hline & & Ethylacetate+ Hexan & 227.56 & 198.56 & 236.65 & 0.9616 & 0.8390 & A \\
\hline & & DCM +Methanol & 164.86 & 224.35 & 225.80 & 0.7301 & 0.9936 & A \\
\hline & & DCM +Ethyl acetate & 164.86 & 201.52 & 160.75 & 1.0256 & 1.2536 & $\mathrm{~S}$ \\
\hline & & Methanol + Aqueous & 224.45 & 259.58 & 263.15 & 0.8453 & 0.9864 & A \\
\hline Pyr $+N$. tabaccum & 1:1 & DCM + Aqueous & 164.86 & 259.58 & 155.80 & 1.0582 & 2.6164 & $\mathrm{~S}$ \\
\hline & & Methanol +Ethyl acetate & 224.45 & 201.52 & 160.75 & 1.0256 & 1.2536 & $\mathrm{~s}$ \\
\hline & & Methanol + Hexane & & 235.85 & 231.65 & 0.9360 & 0.9924 & A \\
\hline & & Ethylacetate+ Hexane & 227.56 & 235.85 & 241.45 & 0.9425 & 0.9768 & A \\
\hline & & DCM +Methanol & 164.65 & 224.35 & 149.35 & 1.1292 & 1.5022 & $\mathrm{~S}$ \\
\hline & & DCM +Ethyl acetate & 164.65 & 201.52 & 211.55 & 0.7972 & 0.9526 & A \\
\hline E. camald. $+N$. & & DCM + Aqueous & 164.86 & 259.58 & 158.43 & 1.0406 & 1.6385 & $\mathrm{~S}$ \\
\hline tabaccum & $1: 1$ & Methanol + Aqueous & 222.45 & 259.58 & 264.65 & 0.8483 & 0.9808 & A \\
\hline & & Methanol + Hexane & 197.46 & 235.85 & 220.75 & 0.8945 & 1.0684 & SA \\
\hline & & Ethylacetate+ Hexane & 260.56 & 235.85 & 262.60 & 0.9922 & 0.8981 & A \\
\hline
\end{tabular}

Key: S- Synergistic; A - Antagonistic; SA- neither Synergistic nor Antagonistic

Of the five highest synergistic activities to note are the following combinations in their order: pyrethrum DCM extract + Eucalyptus camaldulensis methanol extract; pyrethrum DCM extract + Eucalyptus camaldulensis ethyl acetate extract; pyrethrum DCM extract + Eucalyptus camaldulensis hexane extract; pyrethrum DCM extract + Nicotiana tabaccum hexane extract and Eucalyptus camaldulensis DCM extract + Nicotiana tabaccum hexane extract. All these combinations yielded 100\% larval mortality at the concentrations of $118.65,121.45,127.85$, 130.78 and 135.55 ppm respectively. These were indeed reduced concentrations compared to those used as individual extracts. From table 1 individual extracts activities are high: pyrethrum DCM (164.86 ppm); E. camaldulensis methanol (197.46 ppm); Eucalyptus camaldulensis ethyl acetate (260.56 ppm); and $E$. camaldulensis - hexane (198.56 ppm); and N. tabaccum hexane (235.85 ppm). This comparison raises the need for combination extracts as they proof to be economical. From the above highest synergistic activities it is observed that DCM extract of pyrethrum is a synergist (as it appears 5 times in the highest 5 activities shown above) and DCM extract of E. Camaldulensis is another synergist (as it appears once in the highest 5 activities shown above). Even in the lower activities DCM extract of all the plants is seen to be useful. 


\section{International Journal of Science and Research (IJSR) \\ ISSN (Online): 2319-7064}

Index Copernicus Value (2013): 6.14 | Impact Factor (2015): 6.391

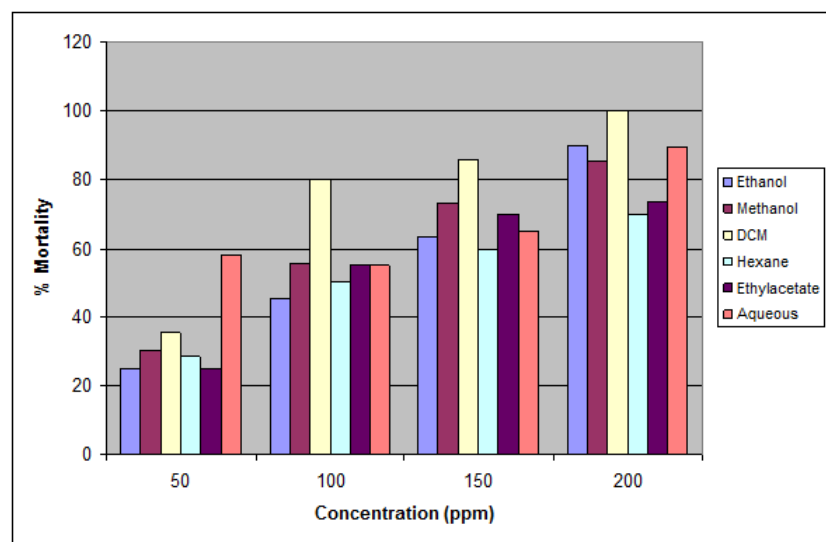

Figure 4: Pyrethrum crude leaf extracts against mortality of third instar larvae of An. gambiae s.s. Giles using various concentrations.

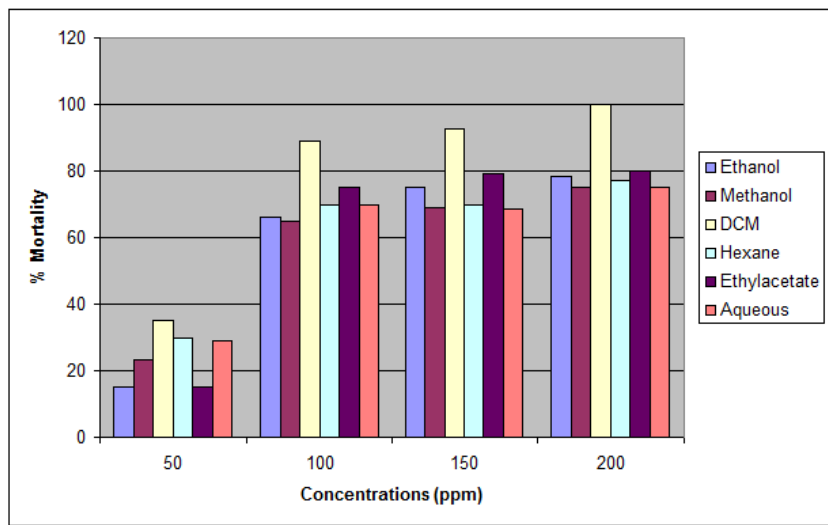

Figure 5: E. camaldulensis crude leaf extracts against mortality of third instar larvae of An. gambiae s.s. Giles using various concentrations.

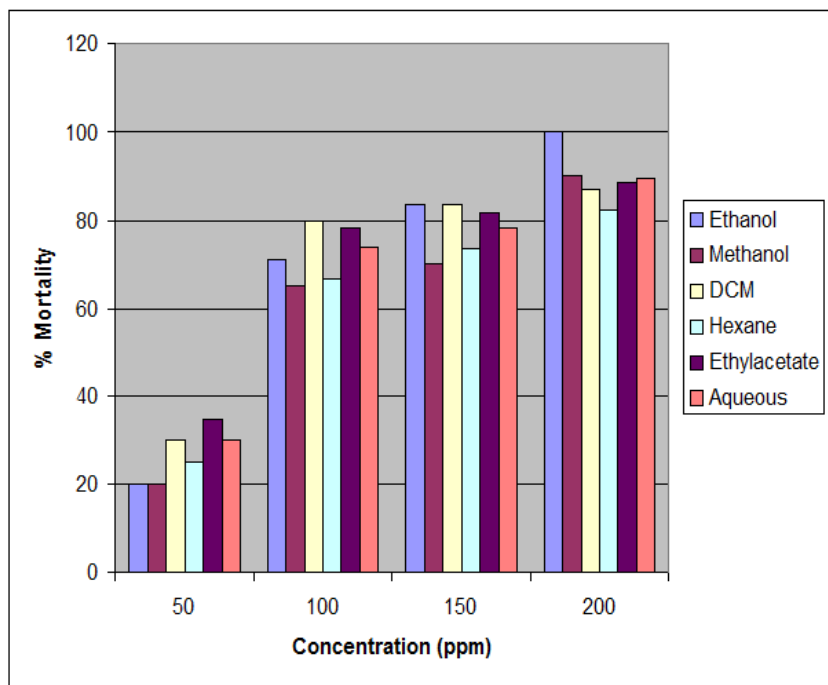

Figure 6: Nicotiana tabaccum crude leaf extracts against mortality of third instar larvae of An. gambiae s.s. Giles using various concentrations.

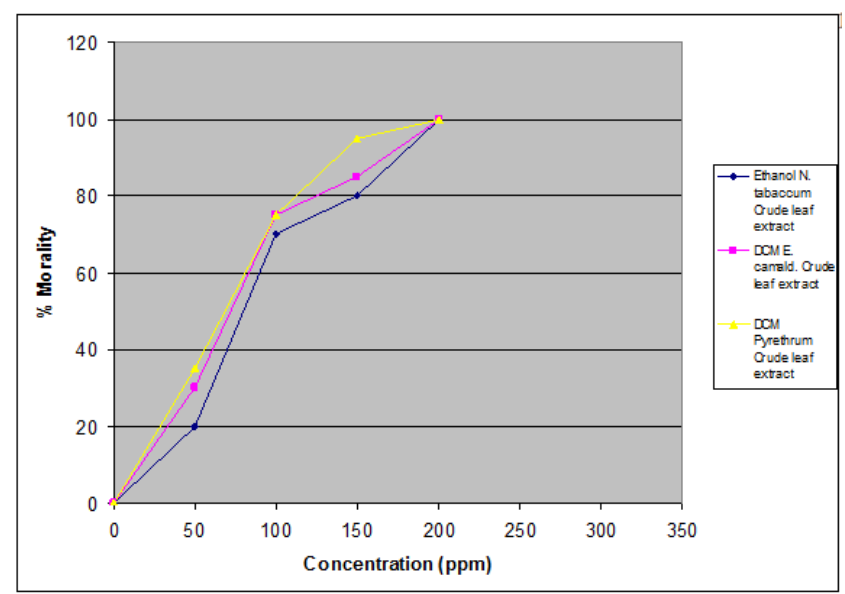

Figure 7: Percentage mortality of third instar larvae of $A n$. gambiae s.s. Giles against crude leaf extracts of Ethanol $N$. tabaccum, DCM E. camald. and DCM pyrethrum



Figure 8: Regression lines (based on Probit analysis) of log concentration of leaf extracts of Pyrethrum ( $y=0.885+$ 2.384X), E. camaldulensis $(\mathrm{y}=0.944+2.481 \mathrm{X})$ and $N$. tabaccum $(\mathrm{y}=1.682+3.637 \mathrm{X}) \mathrm{v} / \mathrm{s}$ percent mortality of third instar larvae of An. gambiae s.s. Giles.

\section{Discussion}

The plants possessing biological activities indicate that they are important for consideration in the aspect of control strategies involved in vector control in terms of feasibility, cost effectiveness and easy availability of plant resources (Kumar et al., 2012) (20). Importantly, section of solvent system for extraction from plants material has impact on resultant efficacy and previous reports on the toxicity evaluation against vector mosquitoes showed that petroleum either was effective than other solvents from plant extraction (Yankamchi, 2009); (21) Sakthivadivel et al., 2012) (22). It is possible that the active components responsible for different bioactivities are extracted in greater measure only with certain specific solvents, and such specificity could be due to the polarity range of the solvents used for extraction. In this experiment DCM extract of pyrethrum and Eucalyptus camaldulensis seemed to posses these qualities. The 24 hours bioassay is a major tool for evaluating the toxicity of Phytotoxins, and a number of researchers have been applying this method to 


\section{International Journal of Science and Research (IJSR) \\ ISSN (Online): 2319-7064 \\ Index Copernicus Value (2013): 6.14 | Impact Factor (2015): 6.391}

assess the toxic effect of different plant extracts on mosquitoes (Remia and Logaswamy, 2010; (23) Sakthivadivel et al., 2012; (24) Patil et al., 2014) (25).

In the acute toxicity of both tests (individual crude leaf extracts and combination) against third instar of $A n$. gambiae s.s. Giles larval mortality increased with increased concentrations of the extracts and similar trend was observed by several researchers in botanicals (Sakthivadival et al., 2012; (26) Kumar et al., 2012; (27) Patil et al; 2014) (28) Observed was that on the exposure to high concentrations, the larval body retracted accompanied with a sluggish behavior (weak), loss of balance (equilibrium) and inability to come on water surface. No doubt the mortality of larvae subjected to the extracts was attributed to the presence of feeding inhibition and / or neorotoxic compounds in the extract agents have proved very effective in the control of various pests (Caraballo, 2000; (29) Seyoum et al., 2001) (30).

\section{Conclusion}

In this study the synergistic mixture of the three plants proved to be toxic to the third instar larvae of An. gambia s.s. Giles. DCM crude leaf extract exhibited the highest activity and hence the search for an alternative effective biopesticide is inevitable. The present results clearly indicated that better alternative and an effective substitute in the form of a synergistic mixture of pyrethrum $-E$. camaldulensis (DCM - Methanol extract; pyrethrum - E. Camadulensis (DCM - Ethylacetate extract); pyrethrum $N$. tabaccum (DCM - Hexane extract) respectively can be used in the control of malaria vector mosquito Anopheles gambia s.s. Giles.

\section{References}

[1] Mueller, I., Zimmerman P.A., Reeder J.C., (2007). Plasmodium Malariae and Plasmodium Ovale the "Bashful, Parasitol, 23: 278-83

[2] Marimuthu G. (2014). Mosquito repellent properties of Delonix elata (L.) gamble (Family: Fabaceae) against filariasis vector, Culex quinquefasciatus Say (Diptera: Culicidae). Asian Pacific Journal of Tropical Disease 2014, 4 (1): 194-198

[3] Becker, N., Petric, D., Zgombua, M., Boasc, C., Dahl, C., Lane, J.et al., (2003). Kluwer Academic/Plenum Publishers, NewYork, 2013

[4] Patel, E.K, Gupta, A., Oswal, R.J. (2012), A review on Mosquito repellent methods. International Journal of Pharmaceutical Chemical and Biological Sciences 2012; 2 (3): 310-317.

[5] Logan, J.G., Birkett, M.A., (2007). Semiochemicals for biting fly control: their identification and exploitation. Pest management science, 2007; 63: 647-657.

[6] Tabashnik, B.E., Finson, N., Johnson M.W., (1991). Managing resistance to Bacillus thuringiensis: Lessons from the Diamond back moth (Lepidoptera: Plutellidae). J. Econ Entomol 24: 49-55.

[7] Sengottyan Senthil Nathan (2007). The use of Eucalyptus tereticornis S.M. (Myrtaceae) oil (leaf extract) as a natural larvicidal agent against the malaria vector Anopheles stephensi Liston (Diptera: Culicidae). Bioresource Tech. 98: 1958-60.

[8] Pushpanathan, T., Jebanesan, A., Govindarajan, M., (2006). Larvicidal, ovicidal and repellent activities of Cymbopogan citratus Stapf (Graminae) essential oil against the filaria mosquito Culex quinquefasciatus Say (Diptera: Culicidae) Trop Biomed 23: 208-12.

[9] Subramonia, T.T, and Katheresan K. (1991). Mosquito larvicidal activity of mangrove plant extracts against Aedes aegypti: Int. Pest Coustr 34: 116-9.

[10] Sumich, J.L., and Morrissey, J.F. (2004). Introduction to the Biology of Marine Life, $8^{\text {th }}$ edn, Jones and Bartlett Publishers, Sandburry.

[11]Park, P.J., Park, E.J., Kim, S.K., Byun, H.G., Jeon, B.T., and Jeon, Y.J., (2005). Reactive oxygen scavenging effect of enzymatic extracts from Sargassum thunbergii. J Agr Food Chem 53: 6666-72.

[12] Xue, G.H., Fang, Y., Lin, H., Chen, L., Li Z.J., Deng, D., and Lu, C.X., (2001). Chemical characters and antioxidative properties of sulphated polysacchrides from Laminaria japonica. J. Appl Phycol 13: 67-70.

[13]Benard, C.B., and Philogene (1993). Insecticide synergists: role, importance and perspectives. $J$ Toxicol Emiron Health 1993; 38: 199-223.

[14] Mohan, L., Sharma, P., and Srivastava, C.N., (2010). Combination larvicidal action of Solanum xanthlocarpum, extract and certain synthetic insecticides against filarial vector, Culex quinquefasciatus Say. Southeast Asian J Trop Med Public Health Vol. 41 No. 2 March, 2010.

[15] World Health Organization (1981). Instruction for determining the susceptibility or resistance of mosquito larvae to insecticide WHO/VBC/81.807.

[16] Kalyanasundaram, M., and Babu (1982). Biologically active plant extracts as mosquito larvicide. Indian $J$ Med Res. 1989:76: 102-106.

[17] Kalyanasundaram, M., and Das, P.K., (1985). Larvicidal and synergistic activity of plant extracts for mosquito control. Indian Journal of Medical Research, 82: 19-23.

[18] Abbott, W.S., (1925). A method of computing the effectiveness of an insecticide. Journal of Economic Entomology, 18: 265-267.

[19] Finney, D.J., (1971). Probit analysis, $3^{\text {rd }}$ ed. Cambridge: Cambridge University Press 13.

[20]Kumar, P.M., Murugan, K. Kovendan, K., Subramaniam, J. and Amaresan, D., (2012). Mosquito larvicidal and pupicidal efficacy of Solanum xanthocarpum (Family: Solanaceae) leaf extract and bacterial insecticide, Bacillus Hurengiensis, against Culex quinquefasciatus Say (Diptera: Culicidae) Parasitology Research, 110: 2541-2550.

[21] Yankanchi, S.R., (2009). Efficacy of different solvents extract of Clerodendrum inerme Gaertn. against larvae of castor semilooper, Achaea janata L. Uttar Pradesh Journal of Zoology, 29 (3): 299-303.

[22] Sakthivadivel, M., Alex Eapen and Dash, A.P, (2012). Evaluation of toxicity of plant extracts against vector of lymphatic filariasis, Culex quinquefasciatus. Indian J Med Res 135, March 2012, pp 397-400 135: 397400 . 


\section{International Journal of Science and Research (IJSR) \\ ISSN (Online): 2319-7064}

Index Copernicus Value (2013): 6.14 | Impact Factor (2015): 6.391

[23] Remia, K.M., and Logaswamy, S., (2010). Larvicidal efficacy of leaf extract of two botanicals against the mosquito vector, Aedes aegypti (Diptera: Culicide). Indian Journal of Natural Products and Resources 1 (2): 208-212.

[24] Patil, P.B., Kallapur, S.V., Kallapur, V.L., and Holihosur, S.N., (2014). Clerodendron inerme Gaertn. plant as an effective natural product against dengue and financial vector mosquitoes. Asian Pacific Journal of Tropical Disease, 4 (Suppl 1): 5453-5462.

[25] Caraballo, A.J., (2000). Mosquito repellent action of Neemos. Journal of American Mosquito Control Association, 16 (1): 45-46.

[26] Seyoum, A., Paleson, K., Kung'a, S., Kabiru, EW., Lwande, W., Killeen, G.F., Hassanali, A., and Knols, B.G.J., (2002). Traditioanl use of mosquito repellent plants in Western Kenya and their evaluation in semifield experimental huts against Anopheles gambiae: ethnobotanical studies and application by thermal expulsion and direct burning. Transactions of the Royal society of Tropical Medicine and Hygiene 96 (3): 225-231 